\title{
Evaluation of Prevention Bundle Application for Ventilator-Associated Pneumonia in Intensive Care Units
}

\author{
Ilknur Esen Yildiz ${ }^{1}$, Hava Yilmaz ${ }^{1}$, Ahmet Dilek ${ }^{2}$, Saban Esen $^{1}$, Mustafa Sunbul $^{1}$, \\ Hakan Leblebicioglu ${ }^{1}$ \\ ${ }^{1}$ Department of Clinical Microbiology and Infectious Diseases, Medicine Faculty of Ondokuz Mayis University, Samsun, Turkey \\ ${ }^{2}$ Department of Anesthesiology and Reanimation, Ondokuz Mayis University School of Medicine, Samsun, Turkey
}

\section{Email address:}

iesenyildiz61@gmail.com (I. E. Yildiz), hyilmaz@omu.edu.tr (H. Yilmaz), adilekdr@yahoo.com (A. Dilek), sabanes@omu.edu.tr (S. Esen), msunbul@omu.edu.tr (M. Sunbul), hakanomu@yahoo.com (H. Leblebicioglu)

\section{To cite this article:}

Ilknur Esen Yildiz, Hava Yilmaz, Ahmet Dilek, Saban Esen, Mustafa Sunbul, Hakan Leblebicioglu. Evaluation of Prevention Bundle Application for Ventilator-Associated Pneumonia in Intensive Care Units. Journal of Family Medicine and Health Care.

Vol. 1, No. 2, 2015, pp. 27-32. doi: 10.11648/j.jfmhc.20150102.13

\begin{abstract}
Objective: The current study investigated the applicability of the VAP prevention bundle and its effect on rates of VAP. Methods: This study was performed in the intensive care units (ICU) of anesthesia (AICU) and the neurology (NICU) in the Medical Faculty of Ondokuz Mayis University from October 2011 to September 2012 (for one year). Mechanically ventilated patients in the ICU for 48 hours were included. The bundle components were patient's head elevated to $30-45^{\circ}$, assessment of daily extubation status (weaning), peptic ulcer prophylaxis, deep vein thrombosis (DVT) prophylaxis, and oral care with chlorhexidine. The VAP rate and ventilator usage rates were calculated and compared in quarterly periods for one year. Results: In the study, 35 patients developed VAP. There was full compliance with the prevention bundle in $30.5 \%$ of cases. No VAP developed in 51 patients whose compliance with the prevention bundle was $100 \%$. In patients ( $\mathrm{n}=35$ ) whose compliance with prevention bundle was more than $50 \%$, VAP $(n=6)$ developed in $19 \%$ of the patients. But, in patients $(n=35)$ whose compliance with prevention bundle was less than $50 \%$, VAP $(n=29)$ developed in $82.8 \%$ of the patients. There was a significant relationship between compliance with the prevention bundle and development of $\operatorname{VAP}(\mathrm{P}<0.05)$. Conclusion: VAP rates reduced by the end of the one-year. To reach a zero infection target, ensuring and maintaining full compliance with all components of the prevention bundle are essential.
\end{abstract}

Keywords: Ventilator-Associated Pneumonia, Prevention Bundle, Intensive Care Units, VAP Rate

\section{Introduction}

Ventilator-associated pneumonia (VAP) is one of the most common infections encountered in healthcare services and has a high mortality rate. Several campaigns, including training, have been initiated for the prevention of VAP, and it has been demonstrated that VAP rates could be reduced, or even set to zero by applying prevention bundles $(1,2)$. For this purpose, hospitals have started to apply prevention bundles established by the Institute for Healthcare Improvement (IHI) in the U.S. (3). In recent years, several bundle applications with different components have been used (4). According to the surveillance data of our hospital, VAP rates are rather high when compared to the rates in developed countries (1). Our study investigated the applicability of the VAP prevention bundle developed by the IHI and its effect on the VAP rate.

\section{Material and Method}

This was a prospective monitoring study performed in the anesthesia intensive care unit (AICU) and the neurology ICU (NICU) of Ondokuz Mayıs University Faculty of Medicine from October 2011 to September 2012. Approval for the study was obtained from the Medical Research Ethics Committee of Ondokuz Mayıs University Faculty of Medicine (Approval No.: 2011/354). The AICU contains 15 beds, and the NICU has 13 beds. One nurse is assigned to 3 patients in the AICU during the day and to 4 patients at night-time. In the NICU, there are 4 patients per nurse during the day and 5 at night-time.

Patients aged 18 years and over who remained in the ICU for $\geq 48$ hours and were mechanically ventilated were included to the study. VAP was diagnosed according to the criteria of 
the Centers for Disease Control (CDC) (5). The VAP rate was calculated by the number of infections observed/days of ventilator usage $\times 1000$. The rates of mechanical ventilator use were calculated as ventilator usage rate $=$ ventilator usage days/patient days. The ICU hospitalization day when VAP developed was determined. The patients in the ICUs were assessed in 2 groups according to their periods on the ventilator. The VAP rates and the ventilator usage rates were calculated for one year in quarterly periods. Surveillance data from the previous year were also calculated. The study was conducted in two parts. One part was composed of training, and the second part involved monitoring whether the prevention bundle was applied. The prevention bundle used in this study was the revised 2010 version of the IHI (3). The components of the bundle were:

1. Patient's head elevated to $30-45^{\circ}$

2. Daily sedation interruption and assessment of daily extubation status (weaning).

3. Peptic ulcer prophylaxis (this component was determined according to whether patients received proton pump inhibitor or $\mathrm{H}_{2}$ receptor blockers. These drugs usage of patients were controlled in per day)

4. Deep vein thrombosis prophylaxis (DVT) (this component was determined according to whether patients received heparin. The heparin usage of patients was controlled in per day)

5. Oral care with $0.2 \%$ chlorhexidine ( 3 times a day during each shift).

Training of the healthcare employees in the ICUs commenced in October 2011. During the training, the employees received information on methods of protection from VAP and on the application of the prevention bundle. Before the training study, a survey was conducted to measure the knowledge level of doctors and nurses in the ICUs. During the training, seminars were delivered, posters were prepared for the units, and one-to-one bedside application of the bundle was performed. The most important part of the training was hand hygiene. The staff were continually reminded of the importance of 5 aspects of hand hygiene and given practical demonstrations. To enhance awareness of hand hygiene, reminders were entered in PCs, and reminder cards were placed near washbasins. An infection control nurse was responsible for ensuring compliance with hand hygiene with informed monitoring. We quarterly performed an observational and cross-sectional study of compliance with hand hygiene and non-informed monitoring. Aspiration compliance was also followed-up within this period. The training was augmented by surveys conducted at quarterly intervals to determine the current knowledge level of the ICU staff.

Compliance with the bundle components was monitored twice daily (morning and afternoon) during the week and once at the weekend. Compliance with each component of the bundle was recorded on an observation form throughout the hospitalization period. Compliance with the components of the prevention bundle was classified into three categories: full compliance, defined as $100 \%$ compliance with all components throughout the hospitalization in intensive care; partial compliance, defined as more than $50 \%$ compliance with all components throughout the hospitalization; and noncompliance, defined as compliance less than $50 \%$. Measurements of the cuff pressure of the intubation tube were performed daily. In addition, data were obtained on patient related risk factors, such as age, gender, tracheostomy, re-intubation, additional niduses, pre-VAP history of antibiotics usage, and presence of trauma.

\section{Statistical Analysis}

The Mann-Whitney $U$ test was used for continuous variables, and a chi-square test was used for categorical qualitative variables. The Kruskal-Wallis test was used to compare the application rates of the components of the bundle and the effect of the application of the bundle on VAP rates. A $P$ value $<0.05$ was considered significant for all statistical tests All statistical tests were performed by Statistical Package for Social Sciences (SPSS) software, USA, for Windows, version 20.0 .

\section{Results}

One hundred sixty-seven of 872 patients monitored in the study period (1 October 2011 to 31 September 2012) met the inclusion criteria and were included to the study. Of these, 35 developed VP. The first quarterly VAP rate was 22.1 for 1000 ventilation day in the AICU and 10.8 in the last quarter. The rate of VAP in the first quarter was 6.5 in the NICU and 0 in the last quarter. The ventilator usage rate was 0.42 in the AICU in the first quarter and 0.34 in the last quarter; these rates were 0.36 and 0.13 in the NICU. Table 1 presents the VAP rates and the ventilator usage rates for both ICUs for September 2010-2011 compared with September 2011-2012.

Table 1. Yearly VAP rates and ventilator usage rates in the ICU.

\begin{tabular}{lllll}
\hline Parameters & AICU* & NICU $\dagger$ \\
\cline { 2 - 5 } & $\mathbf{2 0 1 0 - 2 0 1 1}$ & $\begin{array}{l}\text { 2011-2012 } \\
\text { (Study } \\
\text { period) }\end{array}$ & $\mathbf{2 0 1 0 - 2 0 1 1}$ & $\begin{array}{l}\mathbf{2 0 1 1 - 2 0 1 2} \\
\text { (Study } \\
\text { period) }\end{array}$ \\
\hline VAP $\ddagger$ & 58 & 28 & 9 & 7 \\
$\begin{array}{l}\text { VAP rate } \\
\begin{array}{l}\text { Device } \\
\text { usage rate }\end{array}\end{array}$ & 25.1 & 18.3 & 20.8 & 9.3 \\
$\begin{array}{l}\text { Total } \\
\text { ventilator } \\
\text { days }\end{array}$ & 2310 & 1527 & 0.04 & 0.20 \\
\hline
\end{tabular}

*AICU: Anesthesia intensive care unit, $†$ NICU: Neurology intensive care unit, †VAP: Ventilator-associated pneumonia.

VAP rates in both intensive care units in quarterly periods are shown in Figure 1. The mean hospitalization duration of the patients who developed VAP was $37.8 \pm 32$ (5-122) days, and it was 15.4 $\pm 18.3(4-161)$ days for the patients who did not develop VAP $(\mathrm{P}<0.05)$. VAP developed on the $11.9 \pm 10.4$ (5-87) day of mechanical ventilation. Most of the patients had late-onset VAP. The parameters included in the prevention 
bundle application and their rates of application to the patients are shown in Table 2. In the prevention bundle, compliance with the following was $100 \%$ : patient monitoring in the half-sitting position, proton pump inhibitor usage, and oral care with chlorhexidine. There was a statistically significant relationship between the rates of compliance with DVT prophylaxis, sedation interruption, weaning application and non-development of VAP $(\mathrm{P}<0.05)$. When comparing the effects of the all bundle components on VAP, no VAP developed in 51 patients who were full compliance with the prevention bundle. In patients $(n=35)$ whose compliance with prevention bundle was more than $50 \%$, VAP $(n=6)$ developed in $19 \%$ of the patients. But, in patients $(n=35)$ whose compliance with prevention bundle was less than 50\%, VAP $(n=29)$ developed in $82.8 \%$ of the patients.

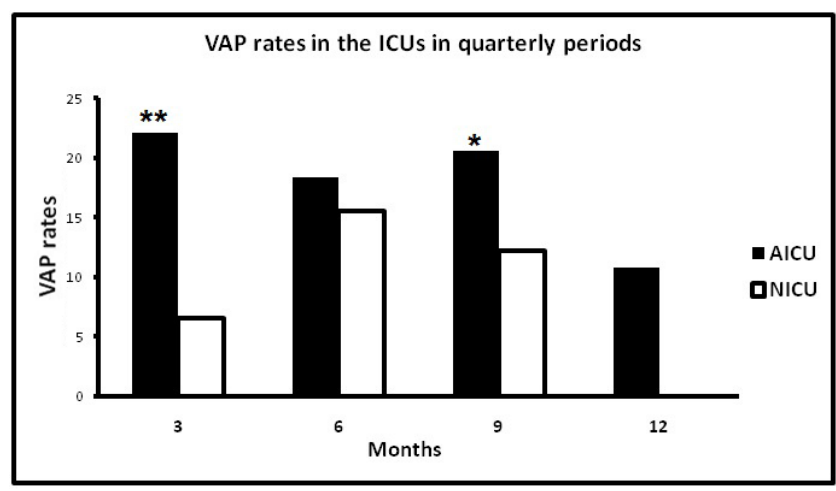

Figure 1. VAP rates in the ICUs in quarterly periods. (AICU: Anesthesia intensive care unit, NICU: Neurology intensive care unit). * and ** show significant differences between VAP rates of both intensive care units at 0.05 and 0.01 levels, respectively.

Table 2. Application rates of the parameters included in the prevention bundle.

\begin{tabular}{llll}
\hline Parameters & $\begin{array}{l}\text { Full } \\
\text { compliance }\end{array}$ & $\begin{array}{l}\text { Partial } \\
\text { compliance }\end{array}$ & Noncompliance \\
\hline $\begin{array}{l}\text { Deep vein } \\
\text { thrombosis } \\
\text { prophylaxis }\end{array}$ & $65.9 \%$ & $20.4 \%$ & $13.8 \%$ \\
$\begin{array}{l}\text { Position } \\
\text { Chlorhexidine usage }\end{array}$ & $100 \%$ & - & - \\
$\begin{array}{l}\text { Proton pump } \\
\text { inhibitor usage }\end{array}$ & $100 \%$ & - & - \\
$\begin{array}{l}\text { Sedation } \\
\text { interruption }\end{array}$ & $24.2 \%$ & $49.5 \%$ & - \\
$\begin{array}{l}\text { Weaning } \\
\text { Compliance with all } \\
\text { components }\end{array}$ & $31.9 \%$ & $32.5 \%$ & $26.3 \%$ \\
\hline
\end{tabular}

In a cross-sectional study performed in the quarterly period after the training, hand washing rates were $4 \%$ before contact with the patient and 55\% after contact. Full compliance with the components of hand hygiene following an informed observation of personnel by an infection control nurse was $71 \%$, whereas it was $10 \%$ when the personnel were not informed about observation. Sixty aspiration procedures were monitored. The pre-procedure compliance with hand hygiene was $16.7 \%$, and the compliance with aspiration techniques was $16.7 \%$. (6)
Hand hygiene compliance rates were $50 \%$ in two intensive care unit before the observational study. During quarterly periods of the study hand hygiene compliance was determined as respectively $51.5 \%, 70.1 \%, 63.8 \%$ and $64 \%$. There were no statistically significant difference before and after the observational study in spite of hand hygiene training programme $(\mathrm{p}>0.05)$. The characteristics of the patients who developed VAP and of those who did not develop VAP are provided in Table 3 .

Table 3. Characteristics of patients who developed VAP (Ventilator-associated pneumonia) and of those who did not develop VAP and their assessment by univariate analysis.

\begin{tabular}{|c|c|c|c|c|}
\hline Parameters & $\begin{array}{l}\text { General } \\
(n=167)\end{array}$ & $\begin{array}{l}\text { VAP (-) } \\
(n=132)\end{array}$ & $\operatorname{VAP}(+)(n=35)$ & $P$ value \\
\hline Mean age & $53.2 \pm 9.2$ & $51.5 \pm 19.7$ & $53.7 \pm 19.8$ & $>0.05$ \\
\hline $\begin{array}{l}\text { Gender } \\
\text { (male/female) }\end{array}$ & $93 / 74$ & $71 / 61$ & $22 / 13$ & $>0.05$ \\
\hline Re-intubation & $36.5 \%$ & $30.5 \%$ & $57.1 \%$ & $<0.05$ \\
\hline Tracheostomy & $17.3 \%$ & $13.7 \%$ & $28.5 \%$ & $<0.05$ \\
\hline Head trauma & $17.3 \%$ & $15.2 \%$ & $25.7 \%$ & $>0.05$ \\
\hline $\begin{array}{l}\text { General body } \\
\text { trauma }\end{array}$ & $20.9 \%$ & $19.8 \%$ & $25.7 \%$ & $>0.05$ \\
\hline $\begin{array}{l}\text { Additional } \\
\text { niduses }\end{array}$ & $74.9 \%$ & $74.1 \%$ & $80 \%$ & $<0.05$ \\
\hline $\begin{array}{l}\text { Pre-VAP } \\
\text { antibiotics } \\
\text { usage }\end{array}$ & - & - & $\begin{array}{l}\text { Patients who } \\
\text { received no } \\
\text { antibiotics: } \\
31.4 \% \\
\text { Patients who } \\
\text { received } \\
\text { antibiotics: } \\
68.6 \%\end{array}$ & $<0.05$ \\
\hline $\begin{array}{l}\text { Cuff pressure } \\
\text { measurement }\end{array}$ & $61.4 \%$ & $68 \%$ & $37.1 \%$ & $<0.05$ \\
\hline
\end{tabular}

The mortality rates were $56.8 \%$ in the group who did not develop VAP, and they were $74.2 \%$ in the VAP group. The difference between VAP and mortality was statistically significant $(\mathrm{P}<0.05)$.

\section{Discussion}

Follow-up of care of patients in the ICU is important to prevent complications that may occur. Moreover, infections associated with healthcare services are considered medical errors $(7,8)$. VAP, which is the most common intensive care infection, prolongs the period of mechanical ventilation and hospitalization in the ICU. The high morbidity and mortality due to VAP and the increase in multiple drug resistance to treatment necessitate simple, easily applicable infection prevention bundles. For this purpose, several care and prevention bundle applications have been developed $(1,4,9)$.

This study aimed to reduce the rate of VAP in our hospital by using a prevention bundle for the first time. The first quarterly VAP rate of 22.1 in the AICU was reduced to 10.8 in the last quarter. In the NICU, it was 6.5 in the first month and " 0 " in the last quarter. Due to the training and the application of the bundle in both ICUs, there was a reduction in the VAP rate in the study period in comparison to data from the previous year. However, our VAP rates are still above 
hospital data reported by the USA National Health Security Network (NHSN) and by other hospitals in Turkey $(10,11)$. To reach required target levels, time and additional studies are required. To ensure the efficacy of prevention bundle, the gold standard is that all components of the preventive package should be applied. Low full compliance with the bundle explains the high rates of VAP rates in the present study. Moreover, fewer nurses, with numbers lower than those employed in other ICUs, may be an additional factor in the high VAP rates. The NHSN reported more than 3525 VAP cases in the U.S. in 2010, with an incfidence range of 0-5.8 per day per 1000 ventilator applications in various hospital units (10). In a multicenter study of ICUs in Turkey that investigated hospital infections associated with mechanical ventilation, Leblebicioglu et al. reported a VAP rate of 26.5 cases per 1000 ventilator-days in 2007 (12). Üstün et al. from Turkey reported a rate of 26,8 cases per 1000 ventilator-days in 2008 (13). In a thesis study conducted at Hacettepe University, Turkey, the investigators reduced the rate from 14,7 to 3.28 cases per 1000 ventilator-days after five years of education and bundle approach in 2010 (14).

In many studies, investigators have applied prevention bundles appropriate to the individual hospitals and determined the reduction in VAP rates. Lawrence et al. compared the efficacy of 10 different bundle applications in VAP prevention in a 2011 study and reported a reduction of $34-85 \%$ in VAP incidence (1). In our study, a reduction of $55.3 \%$ and $27.1 \%$ was achieved in the NICU and AICU, respectively. In the study by Younguist et al. targeting zero infection in prevention bundle application, the VAP rate fell from 2.7 to 0 for per 1000 ventilator days (15).

VAP rates in AICU were higher than those in NICU in this study. VAP rates in surgical ICUs were reported to be higher than those in other ICUs $(1,2)$. The higher rates may be due to the loss of the swallowing reflex, impairment in respiratory functions, and an increased need for invasive intervention because of anesthesia or the intensive use of sedatives (16). In AICU, where this study conducted, mainly the postoperative brain surgery, general surgery, orthopedics, and trauma patients are followed, whereas NICUs contain patients with medical diseases. The difference in the VAP rate in the current study in the AICU and the NICU (18.3 vs. 9.3, respectively) may be explained by the effect of co-morbid factors in surgical units on the application and success of the prevention bundle. In a study following up 112 ICU patients for 550,800 ventilator days in the U.S., the lowest number of VAP cases was observed in cardiology ICUs. When compared to other ICUs, the VAP rate was $4 \%$ higher than in internal medicine ICUs and 59\% more than in surgical ICUs (2). In another study, the VAP rate was 1.7 in internal medicine ICU and 19.3 in surgical ICU. Following the application of a prevention bundle, a greater reduction in the rate of VAP was detected in the internal medicine ICUs than in the surgical ICUs (1).

In our study, the mean intensive care hospitalization period and the mechanical ventilation period of the patients who developed VAP was higher than those of the patients who did not develop VAP, and VAP prolonged both periods. The duration of mechanical ventilation is known to increase the likelihood of VAP. In our study, the mean mechanical ventilation period in the patients who developed VAP was longer apparently. VAP developed on the $11.9^{\text {th }}$ day on average. Therefore, most of our patients were late-onset VAP. Various studies have reported that VAP prolongs the hospitalization period (17-20). VAP did not develop in any patient in the current study where there was full compliance with the bundle, and the frequency of VAP increased as compliance decreased. In particular, full compliance with the bundle was low (30.5\%) in DVT prophylaxis, sedation interruption, and weaning applications. Full compliance cannot be assured due to the daily needs of patients, their clinical status, and contraindications, such as their underlying diseases. Many studies have reported different rates of compliance with prevention bundles. In the U.S., Youngquist et al. reported a compliance rate of $100 \%$, and also in U.S (14). Bonello et al. reported a rate of $82 \%(21)$. In a multicenter study conducted in U.S. and Canada by Resar et al. 95\% compliance with a post-training prevention bundle secured a significant decrease in VAP rates (22). These results suggest that compliance with the bundle is better in developed countries.

It is not easy to ensure bundle compliance. It requires intense effort, as well as time. Hampton et al. reported a study of personnel and family members who underwent extra training for one year and found that it resulted in compliance nearing $100 \%$ (23). In their multicenter study, Leblebicioglu et al. reduced the VAP rate from 31.1 to 16.8 at the end of a study period of 5 years 4 months and determined that the maximum reduction was observed at the end of the study (24). Various difficulties are encountered in compliance. Beattie et al. found that compliance with parameters did not increase in a short period (5). In another study, in Spain, the compliance was low (53\%), because of low trust of doctors to the current studies, material deficiencies in ICU, and concern about cost increase (25).

In our study, the mortality rate in VAP patients was $74.2 \%$. It is difficult to infer a relationship between the development of infection and mortality due to conditions such as trauma, underlying disease, and co-morbidity. Several studies reported that VAP increases mortality. The death rate was $4 \%$ in ventilated patients without pneumonia (26) and 50\% in VAP patients (27). According to a study conducted in Turkey, $87 \%$ of patients who developed VAP died (28).

The nosocomial infection rates in ICUs may be affected by differences in the physical structure of the ICU, in the number of personnel, and in characteristics such as compliance with infection control preventions $(12,29,30)$. During the study period, it has been observed that compliance with care decreases in particular at night and on weekends. Infection rates were also found to increase around official holidays and during annual leave periods when there are fewer nurses working due to deficiencies in compliance with general infection control preventions, particularly hand hygiene. Therefore, one way of reducing infection rates is to ensure that there are sufficient numbers of healthcare personnel available. 
Another problem observed during the training study was an insufficient level of sterilization and compliance with hand hygiene, especially before invasive interventions (aspiration, etc.). Moreover, we observed that personnel did not wash their hands properly and did not use alcohol-based hand antiseptics as required. This failure is one of the basic factors contributing to high levels of VAP. One way of increasing compliance is to actively include ICU employees in the scope of the program and to repeat training programs at regular intervals.

In the informed hand hygiene observation performed for 3 months by infection control nurse the full compliance rate was $71 \%$, but in non-informed observation performed by infection diseases specialist the compliance rate was $10 \%$. According to these results we suggest that staffs should be aware of always observed and if necessary sanctions are carried out.

For prevention of hospital infections, particularly VAP, effective implementation of infection control programs and inspections are required. Increasing awareness among the whole team of the need for compliance with hygiene practices is only possible with training. Dedicated hygiene training programs need to be established, and the training needs to be continuous. Feedback about usefulness of training should be provided to staffs to improve the compliance with hygiene. Moreover, to be successful, intervention teams involved in the application of prevention bundles should include a broad range of personnel and have the support of all the hospital team, including managers.

In conclusion, our study is the first prevention bundle trial conducted in our hospital. Such trials need to be supported by additional studies that include a greater number of patients and more hospital participation. Although a one-year training program can secure a reduction in VAP rates, ensuring and maintaining full compliance with all components of the prevention bundle are essential to reach the zero infection targets.

According to type of intensive care unit, underlying disease, patient population, adds or extractions can be made to the components of bundle. However, we need more studies about this subject.

\section{References}

[1] Lawrence P, Fulbrook P. The ventilator care bundle and its impact on ventilator-associated pneumonia: a review of the evidence. Nurs Crit Care 2010; 16:222-234.

[2] Berenholtz SM, Pham JC, Thompson DA, Needham DM, Lubomski LH, Hyzy RC, Welsh R, Cosgrove SE, Sexton JB, Colantuoni E, Watson SR, Goeschel CA, Pronovost PJ. Collaborative cohort study of an intervention to reduce ventilator-associated pneumonia in the intensive care unit. Infect Control Hosp Epidemiol 2011; 32:305-314.

[3] 5 million lives campaign. Getting started kit: Prevent ventilator-associated pneumonia how-to guide. Cambridge, MA: Institute for Healthcare Improvement 2010.
[4] Berenholtz SM, Pronovost PJ, Lipsett PA, Hobson D, Earsing K, Farley JE, Milanovich S, Garrett-Mayer E, Winters BD, Rubin HR, Dorman T, Perl TM. Eliminating catheter-related bloodstream infections in the intensive care unit. Crit Care Med 2004; 32:2014-2020.

[5] Tablan OC, Anderson LJ, Besser R, Bridges C, Hajjeh R. Recommendations of $\mathrm{CDC}$ and the healthcare infection control practices advisory committee. Guidelines for preventing health-care-associated pneumonia 2003: recommendations of $\mathrm{CDC}$ and the Healthcare Infection Control Practices Advisory Committee. MMWR Recomm Rep 2004; 53:1-36.

[6] Yildız IS, Esen S, Sunbul M, Yilmaz H, Ulger F, Leblebicioglu H. Yoğun Bakım Ünitelerinde Endotrakeal Aspirasyon İşleminin Standartlara Uyumunun İzlenmesi. EKMUD 2013 Bilimsel Platformu. 2013 Antalya. Poster No:037.

[7] Beattie M, Shepherd A, Maher S, Grant J. Continual improvement in ventilator acquired pneumonia bundle compliance: A retrospective case matched review. Intensive Crit Care Nurs 2013; 28:255-262.

[8] WHO/WPRO/SEARO. Practical guidelines for infection control in health care facilities. Geneva: SEARO Regional Publication 2004; No: 41.

[9] Zingg W, Walder B, Pittet D. Prevention of catheter-related infection: toward zero risk? Curr Opin Infect Dis 2011; 24:377-384.

[10] Dudeck MA, Horan TC, Peterson KD, Allen-Bridson K, Morrel G, Pollock DA, Edwards JR National Healthcare Safety Network (NHSN) report, data summary for 2010, Device-associated module. Am J Infect Control 2011; 39:798-816

[11] National Hospital Infections Surveillance Network (UHESA) Report. Summary Data: 2012. Turkey, Ministry of Health (April 2013:17-18).

[12] Leblebicioglu H, Rosenthal VD, Arikan OA, Ozgültekin A, Yalcin AN, Koksal I, Usluer G, Sardan YC, Ulusoy S. Turkish Branch of INICC. Device-associated hospital acquired infection rates in Turkish intensive care units. Findings of the International Nosocomial Infection Control Consortium (INCC). J Hosp Infect 2007; 65:251-257.

[13] Üstün C, Hoşoğlu S, Geyik MF, Aluçlu MU. Device associated nosocomial infections in norological intensive care unit. Firat Medical Journal 2008; 3:179-182.

[14] Kilinçalp S. Evaluation of prevention bundle application for ventilator associated pnuomonia in internal medicine intensive care unit (thesis). Ankara; Hacettepe University Medicine Faculty 2010

[15] Youngquist P, Carroll M, Farber M, Macy D, Madrid P, Ronning J, Susag A. Implementing a ventilator bundle in a community hospital. Jt Comm J Qual Patient Saf 2007; $33: 219-225$.

[16] American Thoracic Society Infectious Diseases Society of America: Guidelines for the management of adults with Hospital-acquired, Ventilator-associated and Healthcare-associated pneumonia. Am J Respir Crit Care Med 2005; 171:388-416.

[17] Alp E. Nosocomial Pneumonia in Intensive Care Units (thesis) Kayseri: Erciyes University Medicine Faculty 2002. 
[18] Agarwal R, Gupta D, Ray P, Aggarwal AN, Jindal SK. Epidemiology, risk factors and outcome of nosocomial infections in a respiratory intensive care unit in North India. J Infect 2006;53:98-105.

[19] Hugonnet S, Uckay I, Pittet D. Staffing level: a determinant of late-onset ventilator-associated pneumonia. Crit Care 2007; $11: R 80$.

[20] Craven DE, Chroneou A. Nosocomial pneumonia. In Mandell GL, Bennett JE, Dolin R, editors. Principles and Practice of Infectious Diseases. 7th ed. Philadelphia: Churchill Livingstone. 2010. 3717-3724 p.

[21] Bonello RS, Fletcher CE, Becker WK, Clutter KL, Arjes SL, Cook JJ, Petzel RA. An intensive care unit quality improvement collaborative in nine department of veterans affairs hospitals: reducing ventilator-associated pneumonia and catheter-related bloodstream infection rates. Jt Comm J Qual Patient Saf 2008; 34:639-645.

[22] Resar R, Pronovost P, Haraden C, Simmonds T, Rainey T, Nolan T. Using a bundle approach to improve ventilator care processes and reduce ventilator associated pneumonia. Jt Comm J Qual Patient Saf 2005; 31:243-248.

[23] Hampton DC, Griffith D, Howard A Evidence-based clinical improvements for mechanically ventilated patients. Rehabilitation Nursing 2005; 30:160-165.

[24] Leblebicioglu H, Yalcin AN, Rosenthal VD, Koksal I, Sirmatel F, Unal S, Turgut H, Ozdemir D, Ersoz G, Uzun C, Ulusoy S, Esen S, Ulger F, Dilek A, Yilmaz H, Turhan O, Gunay N,
Gumus E, Dursun O, Yilmaz G, Kaya S, Ulusoy H, Cengiz M, Yilmaz L, Yildirim G, Topeli A, Sacar S, Sungurtekin H, Ugurcan D, Geyik MF,Sahin A, Erdogan S, Kaya A, Kuyucu N, Arda B, Bacakoglu F. Effectiveness of a multidimensional approach for prevention of ventilator-associated pneumonia in 11 adult intensive care units from 10 cities of Turkey: findings of the International Nosocomial Infection Control Consortium (INICC). Infection 2012; 41:447-456.

[25] Rello J, Lorente C, Bodí M, Diaz E, Ricart M, Kollef MH. Why do physicians not follow evidence-based guidelines for preventing ventilator-associated pneumonia?: A survey based on the opinions of an international panel of intensivists. Chest 2002;122:656-661.

[26] Kollef MH, Silver P, Murphy DM, Trovillion E. The effect of late-onset ventilator-associated pneumonia in determining patient mortality. Chest 1995; 108:1655-1662.

[27] Rello J, Lode H, Cornaglia G, Masterton RA. European care bundle for prevention of ventilator-associated pneumonia. Intensive Care Med 2010; 36:773-780.

[28] Aybar M, Topeli A Epidemiology of Ventilator Associated Pneumonia in a Medical İntensive Care Unit. Intensive Care Journal 2001; 1:41-66.

[29] Doğanay M. Nosocomial infections in surgery services. ANKEM Journal 2005; 19:154-156.

[30] Yilmaz G, Çaylan R, Ulusoy H, Aydin K, Erciyes N, Köksal I. The Evaluation of ventilator associated pneumonia diagnosed in intensive care unit. Crit Care Med I 2004; 4:131-137. 